\title{
Model of Lesson Study Approach during Micro Teaching
}

\author{
Zanaton H. Iksan ${ }^{1}$, Effandi Zakaria ${ }^{1} \&$ Md. Yusoff Daud ${ }^{1}$ \\ ${ }^{1}$ Faculty of Education, Universiti Kebangsaan Malaysia, Malaysia \\ Correspondence: Zanaton H. Iksan, Faculty of Education, Universiti Kebangsaan Malaysia, 43600 UKM Bangi, \\ Selangor, Malaysia. Tel: 603-8921-6252. E-mail: zanaton.iksan@ukm.edu.my
}

Received: July 22, 2014 Accepted: November 5, 2014 Online Published: December 22, 2014

doi:10.5539/ies.v7n13p253

URL: http://dx.doi.org/10.5539/ies.v7n13p253

\begin{abstract}
Lesson study is a study of teaching to provide learning opportunities for teachers to enhance teachers' professional development. Advantages of this approach have been recommended by the Ministry of Education and implemented in stages in selected schools. Thus, students at the pre-service level should be given the exposure about lesson study. Lesson study was implemented by integrating the micro teaching training for the course curriculum and pedagogy. Students perform simulations in micro teaching for seven weeks. This article discusses the proposed model of lesson study integration in a micro teaching class. In addition, this paper also discusses the reflection of students at each element in this model. The implication of this study is the need for students to be given early exposure to lesson study so that they can apply it directly to their teaching practices.
\end{abstract}

Keywords: curriculum, lesson study, micro teaching, pedagogy, pre-service teacher

\section{Introduction}

Lesson study, called "Jugyokenkyu" in Japanese, means "the study of teaching". The term lesson study was introduced by Makoto Yoshida, an expert with vast experience in this field (Takahashi, Watanabe, \& Yoshida, 2006). Lesson study is a collaborative effort of teachers that can help new and senior teachers develop meaningful learning communities (Fernandez, 2005). Not only that, the lesson study could also be done in collaboration with teachers who teach different subjects at the same school or teachers from different schools who teach the same subjects. However, the most popular lesson study in Japan is a group formed in the school itself.

\subsection{Lesson Study as a Learning Community}

The implementation of lesson study involves a group of teachers who collaborate to make a lesson plan based on the goals that have been agreed upon (Ministry of Education, 2011). Then, the lesson study group observes the teaching of one of the teachers who used lesson plans which had been built together. After the first lesson, teachers can make changes to the lesson plan and improve on a new one. After that, the second lesson plan is implemented based on a new lesson plan. Observations are made on the second lesson plan delivered by different teachers. Discussion is conducted to reflect on the lessons that have been used. The discussion will identify the strengths and the changes that need to be done if the next instruction is to be executed (Fernandez \& Yoshida, 2004).

Lesson study is an alternative that emphasizes social interaction in building teacher knowledge of students' learning and to stimulate the development of teaching practices. The implementation of lesson study provides the opportunities for learning communities to implement partnerships and involve collaborative efforts to improve student learning. The goals set in lesson study allow teachers to determine the best way to improve their teaching practices. Strategies in lesson study produce new ideas in teaching and learning based on the initiative that was taken to better understand the thinking of students (Yoshida, 2002, p. 5). Professional learning communities provide opportunities for teachers to (a) identify the appropriate questions to enhance learning for teachers and students, (b) share experiences in the classroom with a group of friends, (c) identify issues of equality and equivalence, and (d) allow the teacher to learn, implement teaching and enhance student achievement in the classroom (West-Olatunji, Behar-Horenstein, \& Rant, 2008).

Professional learning communities bring changes to the functionality of students and teachers in school. Taylor (2005) states that teachers learning either individually or collectively are tested in a professional learning community. In fact, it is an indicator of academic development. Indeed, the characteristics of learning in 
professional learning communities include: (a) learning is not subject to one strategy or technique alone; (b) social structure provides a space for active learning; (c) linking teacher and student learning, (d) the continuation of teacher learning and students increases along with the support of a collaborative learning culture within the school; and (e) the norms laid out in the school organization is learning partnerships and rather than in isolation.

\subsection{Integration of Lesson Study in Teacher Training}

Lesson study should be exposed at the pre-service level and students should be involved directly in the process of their preparation to become a teacher. The implementation of lesson study in teacher training will involve collaboration between experienced teachers, professors and mentors from the university in the field of education, as well as other educators (Fernandez \& Yoshida, 2004).

Lesson study that is applied in training is to improve students' teaching experiences and to be more meaningful through improving teaching techniques. In addition, this approach gives students the opportunity to collaborate with partners involved during teaching practice (Gurl, 2011), mentors and lecturers. Observations also need to focus on the learning process (West-Olatunji et al., 2008). The evaluation and reflection for each lesson is not only for teachers but also focuses on the development of students' learning. In addition, the lesson study approach can evaluate the idea of teachers in order to enhance their creative and critical thinking, mutual collaboration in finding a solution to a problem and to expand the understanding, skills and abilities of teachers and students. Based on the features of lesson study, it is suitable to be implemented during teacher training to improve the knowledge and experience of pre-service teachers. Thus, this article will discuss the model developed in integrating micro teaching during lesson study in the course curriculum and pedagogy.

\subsection{Lesson Study Model}

"Lesson study" is an approach intended to explore the development of teaching and learning that occurs in the classroom (Fernandez, 2005). This approach can also be used as professional development in schools (Lewis \& Perry, 2006). Lesson study has been developed and used in Japan for more than 130 years (Shimizu, 2006) and currently has been used through the world as a teaching professional development process. This approach provides an opportunity for teachers to explore and examine the development of teaching in more depth and detail in the teaching and learning process. In general, the process of lesson study involves five steps implemented continuously as shown in Figure 1: set goals, develop plans, implement lessons and observations, reflection and make improvement (Stepanek, 2007).

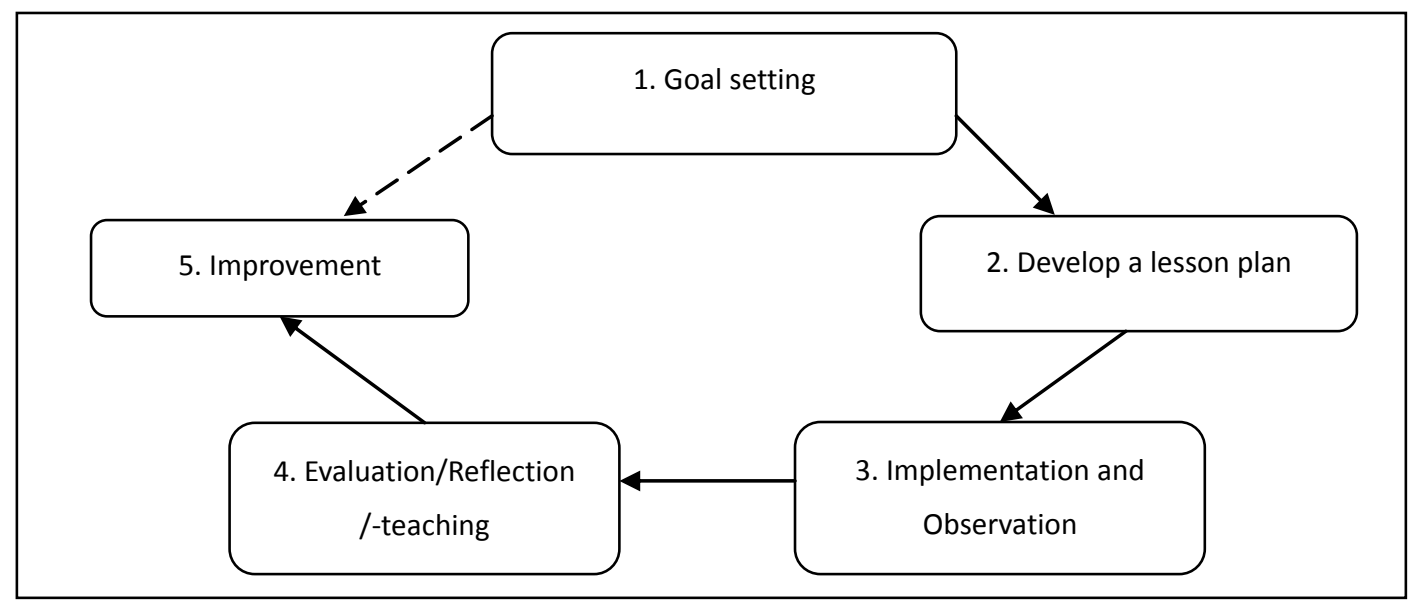

Figure 1. Lesson study model

Lesson study implementation involves several teachers in a teaching session. Iksan (2014) has divided the learning community into two parts, preparation community and research community. The preparation community of teachers is directly involved in every step of the implementation of lesson study, and the research community of teachers in teacher preparation and other communities is invited as a volunteer to observe teaching in the open class. The teachers work together for each teaching session from determining the learning objectives to the reflection.

Based on Figure 1, the first step is to talk to the teacher to determine appropriate instructional objectives with 
targeted students and to determine strategies and teaching aids that will be used to help students understand. There should be a limited number of objectives so that students can understand the teaching and the strategy is more effective for them. The teaching approach should be student-centered as much as possible so that the students are involved actively during class. In the second step, teachers put together a complete lesson plan for the teaching. The collaboration and partnership are expected to generate more brilliant ideas, which result in an interesting lesson plan. The third step, a teacher will implement teaching in a real classroom. Teaching should be based on the lesson plan that has been developed. Another mambers in a group will monitor and evaluate the teaching. They would understand the lesson as they have developed the lesson plan together. Therefore, the observation of students' responses could be done better. After completing the lesson, all students in a class will make a reflection on the teaching and learning and discuss the strengths and weaknesses of their teaching. Thus, enhancement can be made to improve the teaching plan. Next, a second lesson can be done with reference to the lesson plans that have been improved and expanded.

\subsection{Teaching Simulation through Micro Teaching}

The Curriculum and Pedagogy course is one of the basic education courses that are required for all students. This course is to provide knowledge about the components of teaching in the classroom. This course exposes students to the experience of teaching strategies, assessment and various skills in the teaching process (Iksan, 2013; Sulaiman, 2004). All these aspects can be learned by the students more clearly through teaching simulation through micro teaching. Micro teaching emphasizes specific skills in teaching and is implemented for 7-15 minutes of class time. However, students are also exposed to implemented teaching simulation and integrate all the skills learned in 35-40 minute lessons (Iksan, Mohd-Nor, Mahmud, \& Zakaria, 2014)

Micro teaching involves the teaching simulation in class. Implementation of micro teaching from lesson planning followed by implementing the teaching is done on an individual basis. Micro teaching focuses on specific skills, namely: Skills A-Introduction, stimulus variations and descriptions; Skills B-using the blackboard and detection; Skills C-clarifying with an example, reinforcement and monitoring; and Skills D-questioning and monitoring (Iksan, 2013). Table 1 shows the types of skills emphasized and descriptions for each skill.

Table 1. Skills Emphasized During Micro Teaching

\begin{tabular}{|c|c|c|}
\hline Skills & Type of skills & Explanation \\
\hline $\mathrm{A}$ & $\begin{array}{l}\text { Introduction, skills } \\
\text { variations and } \\
\text { description }\end{array}$ & $\begin{array}{l}\text { Introduction to attract attention, arouse interest, and structure. Skills variations } \\
\text { account for the various activities of teachers in terms of gestures, speech } \\
\text { patterns and the use of different senses in order to maintain students' interest. } \\
\text { Teacher's explanation to develop an idea is easy to understand. }\end{array}$ \\
\hline B & $\begin{array}{l}\text { Using white board } \\
\text { and monitoring }\end{array}$ & $\begin{array}{l}\text { Skills in using white board in the aspect of planning, space use, format, } \\
\text { illustration and tidiness. Monitoring student understanding through students' } \\
\text { feedback. }\end{array}$ \\
\hline $\mathrm{C}$ & $\begin{array}{l}\text { Clarify with an } \\
\text { example, } \\
\text { reinforcement and } \\
\text { monitoring }\end{array}$ & $\begin{array}{l}\text { Teacher's explanation uses a related example, is interesting and uses various } \\
\text { materials to increase students' participation. }\end{array}$ \\
\hline $\mathrm{D}$ & $\begin{array}{l}\text { Questioning and } \\
\text { monitoring }\end{array}$ & $\begin{array}{l}\text { Looks at oral questioning skills-wait time, feedback, encouragement, further } \\
\text { explanation, dessiminate questions. }\end{array}$ \\
\hline
\end{tabular}

Micro teaching that involves specific skills will be evaluated by a student and a lecturer. After micro teaching sessions, discussions are conducted with the evaluator's comments.

For teaching simulation that combines all the skills, the teaching is done over a period of approximately 30 to 40 minutes. The time is calculated based on the actual teaching in schools. This lesson involves the four skills involved in teaching: introduction, development, evaluation and closing. Introduction made in the early teaching stages is to attract students' attention. The development of teaching involves processes that occur during teaching, with a focus on how to achieve the planned objectives while integrating various skills in teaching. Skills and learning objectives that are developed in these 30-40 minute lessons are comprehensive.

Thus, "lesson study" is appropriate to be implemented in this micro teaching class to assess the process of teaching 
and pupils' learning. Looking at the advantages found in the lesson study approach, it is suitable to be applied in micro teaching. Thus, application of lesson study in micro teaching is an innovation to improve pre-service teachers' teaching skills during the training.

\section{Methodology}

This research involves the application of lesson study in micro teaching. This study was done to a tutorial group involving 12 students who took the Curriculum and Pedagogy course. The implementation has been integrated with a micro teaching lesson study. Students were divided into three groups and each group consists of three students. Students in each group are required to teach individually. Having experienced individual teaching, students are asked to reflect on their experiences collectively. All students are required to perform micro teaching involving all members.

\section{Findings and Discussion}

Micro teaching with lesson study approach is an innovation in Curriculum and Pedagogy courses. Micro teaching provides the experience for the pre-service teachers to learn a simulation of the concept of teaching and learning. Simulation of the concept of teaching and learning indirectly encourages pre-service teachers to link the knowledge gained from theory to teaching practice (Fernandez, 2006).

\subsection{Lesson Study Model in Micro Teaching}

In this course, students will have to do micro teaching in two modes. In the first mode each student simulates the specific teaching skills. For each skill, students will teach around 7-10 minutes. There are four types of teaching skills to be learned in this course. In the second mode the student will integrate the four skills in a lesson. Lesson study in micro teaching can be done as shown in Figure 2.

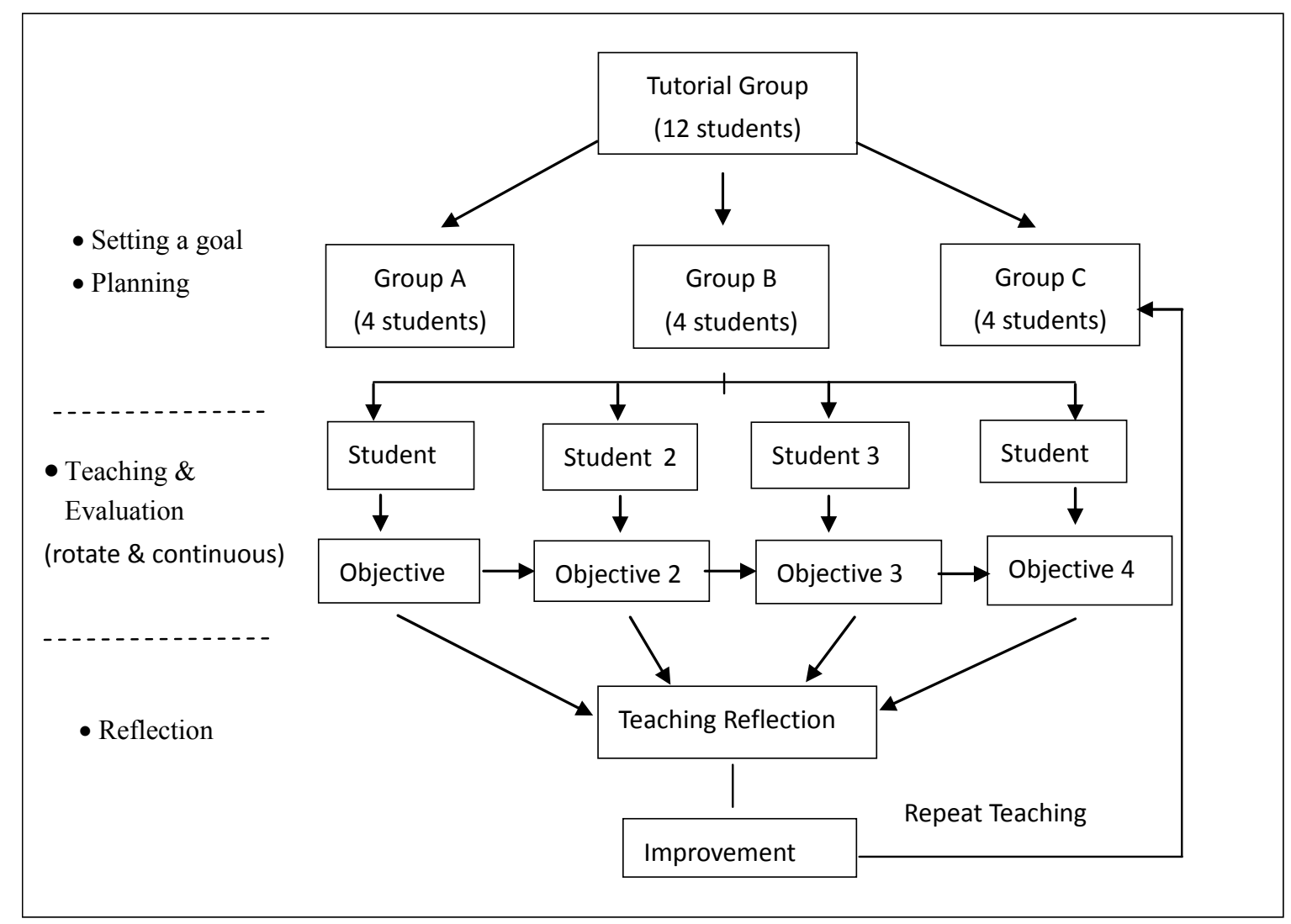

Figure 2. Integration of lesson study and micro teaching model

Integration of lesson study in micro teaching is started with lesson study groups. The students in groups discuss to determine instructional goals and build lesson plans together. Each group provides four objectives of teaching and plans student-centered strategies to achieve each objective. Each student will be taught based on the selected learning objectives. While one student teaches, the other group members become the assessors. A focused 
evaluation is implemented: assessment of teacher communication, student-centered strategies and behavior of students. Members who evaluate students' behavior are also given the task of taking an instructional video. The instructional video will be used for teaching reflection.

\subsection{Formation of Group}

Students were divided into three groups and each consisting of four members. Each member of the group should discuss the teaching goal they set. Among the goals to be achieved are the topic to be selected in the teaching, the syllabus and determining the role of each member of each group. Each member in the groups has his own role during the lesson; other members act as assessors. A focused evaluation is implemented. Each member plays a role to evaluate in terms of communication, strategy and behavior of students. Students are also required to plan the role of each member. Table 2 shows the role of the focused evaluation in a teaching session.

Table 2. The role of each member in the teaching session

\begin{tabular}{lllll}
\hline & Role & & & \\
\hline Objective/Member & 1 & 2 & 3 & 4 \\
Objective 1 & Teacher & $*$ & $/$ & / \\
Objective 2 & $*$ & Teacher & $\#$ & $*$ \\
Objective 3 & $/$ & $\#$ & Teacher & Teacher \\
Objective 4 & $\#$ & $/$ & $*$ & \\
\hline
\end{tabular}

* Questioning skills;

/ Students' behavior;

\# Teaching strategy.

\subsection{Preparation of Lesson Plan}

Each group prepares collaboratively produced lesson plans. They need to provide four learning objectives and determine specific objectives for each member. They also need to plan student-centered strategies for each objective. Students highlight some of the themes in individual teaching plans. They face difficulties and challenges in providing daily lesson plans because they have to think on their own in every step of the lesson. It is reported by the student that it is “... quite challenging to prepare lesson plans ... I need to figure out the overall tone of what to do during the process teaching and learning". In addition, students need other assistance such as finding examples of instructional videos, teacher's advice on how to incorporate blogs into the lesson plan and discuss it with friends. This is explained by the students: "I have seen the video examples of induction set by the teacher on YouTube. Also I read the advice of teachers in a blog and taking his advice to be applied in teaching". The view of students indicates that they need support to create lesson plans. In this case, the lesson study provides students the opportunity to discuss with the current members of the group when preparing a lesson plan.

Through the lesson study approach in micro teaching, things that are highlighted in the lesson plans by the students in the group are sharing of ideas, collaboration in preparation of teaching aids, improvement of lesson plans, joint evaluation and enhancing motivation. The lesson plan that is prepared jointly will establish cooperation in the sharing of ideas between them through collaborative discussions: “...one of the processes in doing daily lesson plans as a group is that we are able to share and gain various ideas; a small idea can be developed further in group discussions". Students are also able to provide interesting teaching aids: "Through preparation of lesson plans together, we can develop an interesting teaching aid". In addition, all the members in a group have the opportunity to evaluate the lesson plans that are developed together when one of the members is teaching. "When in the classroom, other group members can assess the weaknesses and strengths of the teaching techniques that was designed together". This enables them to discuss and to improve lesson plans. Overall, cooperation in preparing lesson plans in the lesson study approach will enhance the motivation and morale of students in the learning process as they are still new in the world of education. "Preparation of teaching plan in group increase motivation among us, as this is our first time in making lesson plans and teaching...indirectly we get encouragement from each other to increase our motivation in teaching effectively in the micro teaching".

\subsection{Teaching Rotation}

The developed lesson plan has four learning objectives. Each member must teach according to the objectives set. 
The teaching rotation is implemented continuously in a teaching session. Students' reflections on teaching are focused on their teaching and learning. In a teaching session, all members have a role: teaching or evaluating. While one student instructs, other students evaluate the instruction. This approach allows each member to focus on teaching. They can focus on student-centered strategies that have been devised. This method can increase the interest and motivation of students because they can learn through the experiences of four student-centered activities which "attract students' attention because different teacher has a different strategy in teaching". This approach also provides members an opportunity to learn from each other and to be able to streamline their teaching as a result of the observation. "Teaching in rotation can teach me to overcome and improve the weakness in terms of proficiency and teaching skills through observation of another friend".

\subsection{Focused Evaluation}

Focused evaluation is done by assigning roles to each member of the group who became the evaluators during the process of teaching. Each assessment focuses on the role given such as oral questioning, communication skills, and student learning. The evaluation focuses on skills that were planned together in teaching the lesson and seeing how well the skills were applied in the teaching process. This means that each assessor will refer to the teacher's lesson plans during evaluation.

Student reflections on focused evaluation are able to do an in-depth evaluation and assessment and results can be applied in teaching. Through a focused evaluation, each evaluator should focus on areas to be assessed in more detail (e.g. ...to ensure that teachers fully use their teaching skills in order to achieve the objectives set). For example, an evaluation on questioning skill will focus on the elements in questioning, the nature of the question, wait time, changing direction and the level of questions. This evaluation will provide knowledge about the skills to the students in more detail. The evaluation done by the members of the group help improve their own teaching “...help myself to improve my weaknesses when looking at other member teaches...” This approach could provide opportunities for students to better learn the elements of teaching skills.

\subsection{Reflection}

All members of the group give reflections in front of the class once the rotation is complete in a teaching session. Reflection begins with self-reflection on teaching teachers to see how well learning objectives have been achieved and their feelings while teaching, followed by the evaluation of each member in the group. Group members may comment on the skills upon which they have jointly agreed and the extent to which they have been implemented. All comments will be recorded by the group for improvements in the next teaching session. Based on Table 3, Sara began self-reflection on his teaching, followed by a reflection on Ain's skills questioning, reflections on Nora in terms of student behavior and reflection on Lin regarding teaching strategy.

Table 3. Rotation for reflection

\begin{tabular}{lllll}
\hline Student & Role & & & \\
\hline & Sara & Ain & Nora & Lin \\
Sara & Guru & $*$ & $/$ & $\#$ \\
Ain & $*$ & Guru & $\#$ & $/$ \\
Nora & $/$ & $\#$ & Guru & $*$ \\
Lin & $\#$ & $/$ & $*$ & Guru \\
\hline
\end{tabular}

* Questioning skills;

/ Student behavior;

\# Teaching strategy.

As a result of this reflection, the students said that reflection activities can increase their knowledge. "Through teaching reflection...I can learn something new in teaching methods". In addition, they also get to know the weaknesses and strengths in teaching more specific because they "...help me see that there are advantages and disadvantages in my teaching". At the same time the discussion on teaching reflection helps improve teaching and teaching plan. "...[They] help me to use the skills proposed".

The discussion on reflection will highlight strengths and weaknesses in the group during the teaching process. At the same time appropriate modification of the teaching can be done easily because all members participated in 
the preparation of lesson plans for the first phase.

\subsection{Teaching Repetition}

Teaching should be done again with regard to the proposed improvements as a result of the comments made by the group partners in the previous lesson. New comments suggested by members of the group are to be included in the lesson plan as an improvement to the next lesson. With these improvements, the students will be more confident and will make sure not to repeat mistakes committed in the previously evaluated teaching. Students from other groups will also benefit from this reflection.

\section{Conclusion}

The lesson study approach in micro teaching is an innovation not only in the evaluation process, but also in increasing the skills of teaching in teacher training. This approach provides a more detailed discussion of mastering the right skills so that students can teach better. The element of reflection in teaching is a good approach because students have the opportunity to reflect on what is good or bad in their teaching, or rather the extent to which it complied with what was planned and what was delivered in a teaching session. The comments from other group members provide useful input to students which they may not have crossed upon earlier in the group discussions during the preparation of the lesson plan. Lastly, it can be concluded that integration of lesson study in the micro teaching class is possible and should be used in the training of pre-service teachers regularly.

\section{References}

Fernandez, C., \& Yoshida, M. (2004). Lesson study: A Japanese approach to improving mathematics teaching and learning. Mahwah, NJ: Lawrence Erlbaum.

Fernandez, M. L. (2005). Learning through microteaching lesson study in teacher preparation. Action in Teacher Education, 26(4), 37-47. http://dx.doi.org/10.1080/01626620.2005.10463341

Gurl, T. (2011). A Model for incorporating lesson study into the student teaching placement: what worked and what did not? Educational Studies, 37(5), 523-528. http://dx.doi.org/10.1080/03055698.2010.539777

Iksan, Z. (2013). Kemahiran A, B, C dan D Pengajaran Mikro. Buku Panduan Pengajaran Mikro (Unpublished document). Fakulti Pendidikan: UKM Bangi.

Iksan, Z. (2013). Proforma Kurikulum dan Pedagogi, Fakulti Pendidikan UKM (Unpublished Document).

Iksan, Z. H., Mohd-Nor, S. N. A., Mahmud, S. N., \& Zakaria, E. (2014). Applying the principle of "Lesson Study" in teaching science. Asian Social Science, 10(4), 108-113. http://dx.doi.org/10.5539/ass.v10n4p108

Lewis, C. C., \& Perry, R. (2006). Professional Development through Lesson Study: Progress and Challenges in the U.S. Apec-Tsukuba International Conference Innovative Teaching Mathematics through Lesson Study, 19-32.

Ministry of Education. (2011). Lesson study: Pembelajaran melalui amalan kolaboratif guru Buku 1. Malaysia: Ministry of Education.

Shimizu, S. (2006). Professional development through lesson study: A Japanese case. Paper presented at the APEC International Syposium on Innovation and Good Practices for Teaching and Learning Mathematics through Lesson Study, Khon Kaen, Thailand.

Stepanek, J. L., Appel, G., Leong, M., Mangan, M. T., \& Mitchell, M. (2007). Leading lesson study: a practical guide for teachers and facilitators. CA: Corwin Press Thousand Oaks.

Sulaiman E. H. (2004). Pengenalan pedagogi. Skudai: Penerbit Universiti Teknologi Malaysia.

Takahashi, A., Watanabe, T., \& Yoshida, M. (2006). Developing good mathematics teaching practice through lesson study: A US perspective. Progress report of the APEC project: A Collaborative Study on Innovations for Teaching and Learning Mathematics in Different Cultures among the APEC Member Economies. Ministry of Education, Culture, Sports, Science and Technology of Japan (MEXT), Japan International Cooperation Agency (JICA): University of Tsukuba, 129-136.

Taylor, A. R., Anderson, S., Meyer, K., Wagner, M. K., \& West, C. (2005). Lesson study: A professional development model for mathematics reform. The Rural Educator, 26(2). 17-22.

West-Olatunji, C., Behar-Horenstein, L., \& Rant, J. (2008). Mediated lesson study, collaborative learning, and cultural competence among early childhood educators. Journal of Research in Childhood Education, 23(1), 96-108. http://dx.doi.org/10.1080/02568540809594648

Yoshida, M. (2002). Developing effective use of the blackboard through lesson study. Resource for Better School. 
Retrieved from https://www.ibo.org/ibap/conference/documents/ShirleyDroeseArticle1.pdf

\section{Copyrights}

Copyright for this article is retained by the author(s), with first publication rights granted to the journal.

This is an open-access article distributed under the terms and conditions of the Creative Commons Attribution license (http://creativecommons.org/licenses/by/3.0/). 